\title{
Właściwości złączy lutospawanych aluminium ze stalą
}

\section{Properties of braze welded joints between aluminum and steel}

\section{Streszczenie}

Cienkie blachy ze stali ocynkowanej łączono ze stopem aluminium za pomoca lutospawania. Zastosowano niskoenergetyczną metodę spawania AC puls MIG z użyciem spoiwa AISi5. Przeprowadzone badania wizualne, metalograficzne i wytrzymałościowe złączy lutospawanych potwierdziły korzystny wpływ łuku pulsującego MIG ze składową prądu zmiennego na właściwości złączy. Badania metalograficzne wykazały wysoką jakość połączeń, bez wewnętrznych niezgodności oraz śladów uszkodzenia warstwy cynku. Średnia wytrzymałość na ścinanie złączy zakładkowych wynosiła ok. $200 \mathrm{MPa}$.

\section{Abstract}

Thin sheet of zinc galvanized steel and aluminum alloy were braze welded. A low-energy AC pulse MIG method of welding with the use of filler metal AISi5 was applied. The visual, metallographic and strength studies of brazed welded joints confirmed the beneficial effect of pulsed MIG arc with an AC component on the properties of the connectors. Metallographic examination showed high quality connections without internal imperfections and signs of damage to the zinc coating. Average strength of lap shear joints was about $200 \mathrm{MPa}$.

\section{Wstęp}

Problemem w łączeniu takich materiałów jak stal z aluminium są najczęściej ich zróżnicowane właściwości fizykochemiczne, które uniemożliwiają wykonanie złącza tradycyjnymi technikami spawalniczymi. Duża ilość ciepła podczas spawania powoduje powstawanie $z$ nadtopionych krawędzi grubej warstwy kruchych faz międzymetalicznych żelaza z aluminium, które dyskwalifikują takie złącza $\mathrm{z}$ zastosowania $\mathrm{w}$ produkcji przemysłowej.

Podstawowym sposobem zapobiegania tworzeniu się kruchych faz jest zastosowanie materiału pośredniego, np. w postaci warstwy cynku na powierzchni stalowych blach ocynkowanych. Tak przygotowane materiały można połączyć jedynie za pomocą zgrzewania, lutowania lub lutospawania.

Dr inż. Piotr Białucki, prof. dr hab. inż. Andrzej Ambroziak, dr inż. Wiesław Derlukiewicz, dr inż. Artur Lange, mgr inż. Michał Glezman - Politechnika Wrocławska.
Zachowanie nieuszkodzonej warstwy cynku możliwe jest przy zastosowaniu do łączenia w procesie lutospawania niskoenergetycznych metod spawania MIG i spoiwa na osnowie aluminium.

W pracy przedstawiono wyniki badań właściwości złączy lutospawanych niskoenergetyczną metodą spawania AC puls MIG z opcją FC (Feed Control), która w sposób istotny poprawia stabilność łuku.

\section{Niskoenergetyczne metody lutospawania}

Rozwój źródeł prądu przyczynił się do powstania nowej generacji urządzeń spawalniczych, których wspólną cechą jest zwiększona kontrola nad ilością ciepła wprowadzaną do strefy łączenia. Jest to korzystne wszędzie tam, gdzie zachodzi konieczność łączenia 
elementów cienkościennych, o grubości często mniejszej niż $1 \mathrm{~mm}$. Urządzenia te umożliwiają również wykonywanie połączeń wcześniej uznawanych za trudne lub wręcz niemożliwe do realizacji ze względów metalurgicznych, jak np. łączenie stali $z$ aluminium.

Małą energię spawania w metodach konwencjonalnych GMAW uzyskuje się w łuku zwarciowym przy niskich parametrach napięciowo-prądowych. Dalsze zmniejszenie energii spawania uzyskano po zastosowaniu łuku pulsującego, który umożliwił pewien wpływ na wielkość oraz ilość kropel metalu przechodzących w łuku do jeziorka spawalniczego. Prawdziwy przełom w kontroli nad energią spawania nastąpił dzięki zastosowaniu cyfrowego sterowania przebiegiem napięcia i natężenia w każdej fazie przejścia kropel metalu w łuku spawalniczym.

Dzięki zastosowaniu cyfrowego sterowania procesem możliwe jest znaczne ograniczenie energii liniowej przez ingerencję w przebiegi parametrów prądowo-napięciowych w czasie cyklu lutospawania. Uzyskuje się wówczas kontrolę nad przechodzeniem kropel metalu spoiwa w łuku. Wraz z postępującą automatyzacją i zwiększoną liczbą robotów przemysłowych, urządzenia takie stanowią przyszłość techniki spawalniczej. Znane są m.in. metody STT firmy Lincoln-Electric, ColdArc - EWM, CMT - Fronius, CBT - Daihen.

W procesie konwencjonalnego spawania łukiem zwarciowym zapewnienie stabilności łuku przy małej energii spawania wymaga, aby przebieg prądu utrzymywał ustawione napięcie na stałym poziomie. Spawanie łukiem zwarciowym charakteryzuje obecność dużej ilości rozprysków, które pojawiają się, gdy dochodzi do zwarcia elektrody z metalem jeziorka. Wysoki prąd zwarcia odrywa krople metalu od drutu, które przechodza do jeziorka spawalniczego, ale jednocześnie silnie je przegrzewa, co sprzyja wybuchowemu rozpryskowi ciekłego metalu. Zwarcia drutu z jeziorkiem zachodzą w sposób niekontrolowany z częstością do $100 \mathrm{~Hz}$, a wielkość odrywanych kropel i ich ilość jest przypadkowa.

W metodzie STT nie utrzymuje się stałego prądu ani stałego napięcia, natomiast kontroluje się przebieg prądu z wysoką częstotliwością w zakresie, w którym moc łuku jest zależna od chwilowego zapotrzebowania, nie zaś, jak w przypadku tradycyjnych źródeł prądu, średniego napięcia prądu stałego. Kształt przebiegu prądu spawania (waveform) jest modyfikowany setki razy w ciągu sekundy, aby przenieść każdą pojedynczą kroplę stopionego metalu oddzielnie, gdy elektroda ulega skróceniu. W ten sposób unika się niekontrolowanych wybuchów i eliminuje rozprysk [4].

W metodzie ColdArc niską energię spawania uzyskuje się, dokonując aktywnej ingerencji w kształt przebiegu wprowadzanej mocy dla całości procesu, tj. fazy łuku i fazy zwarcia.

ColdArc jest zatem metodą łączenia, umożliwiajającą stosowanie niskich natężeń w fazach pomiędzy zwarciami, bez ryzyka nadmiernego topienia drutu i bez uciążliwości gaśnięcia łuku [5].
W przypadku procesu CMT obserwuje się zupełnie nowy sposób oddzielania kropli metalu od drutu elektrodowego. Innowacją tej metody jest bezpośrednie włączenie do kontroli procesu spawania parametru prędkości podawania drutu [6]. Łuk pulsujący w tej metodzie jest połączony $z$ pulsacyjnym podawaniem drutu.

W metodzie CBT kontrolę nad stabilnościa jarzenia się łuku i powstawaniem rozprysków osiągnięto przez korekcję natężenia prądu spawania do optymalnej wartości z użyciem monitorowania zmian napięcia w każdej chwili podczas jarzenia łuku. Pozwala to kontrolować stabilność cyklu przenoszenia metalu podczas zwarcia i podczas ponownego zajarzania łuku. $W$ tej metodzie zmienna ilość ciekłego metalu przenoszonego do jeziorka może być określana w sposób precyzyjny, co pozwala skutecznie przeciwdziałać powstawaniu rozprysków [7].

Badania prowadzone nad kontrolą procesu spawania i ograniczaniem ilości ciepła wprowadzanego do złącza doprowadziły do udoskonalenia znanych już niskoenergetycznych metod spawania, np. CMT Advanced i powstania nowych odmian, w których zastosowano do łuku pulsującego fazę prądu przemiennego, np. w urządzeniu DW300 firmy OTC Daihen. W wyniku regulacji czasu trwania części cyklu, kiedy elektroda jest biegunem ujemnym, kontroluje się ilość energii cieplnej spawania.

\section{Metoda lutospawania zastosowana w badaniach}

Lutospawane złącza próbne ze stali ocynkowanej DC01 ze stopem aluminium 6061 zostały wykonane metodą lutospawania ACP, tzn. łukiem pulsującym z udziałem prądu przemiennego na urządzeniu DW300 firmy OTC Daihen.

Zastosowany w źródle prądu DW300 puls AC jest bardzo zbliżony kształtem do pulsu DC, z tą zasadniczą różnicą, że prąd bazy na wykresie znajduje się po przeciwnej stronie osi 0 , a więc pulsacja odbywa się w zakresach prądu przemiennego. Taka pulsacja pozwala kontrolować przenoszenie kropel i ilość wprowadzonego ciepła, co powoduje przenoszenie jednej kropli ciekłego metalu spoiwa w czasie jednego impulsu, ogranicza wtopienie i zwiększa wydajność topienia drutu. Dzięki niesymetrycznemu kształtowi prostokątnego impulsu prądu $A C$ i regulacji balansu (tj. stosunku czasu jarzenia się łuku DC+ do czasu jarzenia się łuku DC-) oraz offsetu (tj. stosunku napięcia dodatniego do napięcia ujemnego) jest możliwa płynna regulacja szybkości stapiania drutu, głębokości wtopienia, szerokości ściegu i temperatury jeziorka [8].

Przykładowy przebieg zmian prądu spawania łukiem AC puls w urządzeniu DW 300 przedstawiono na rysunku 1. 


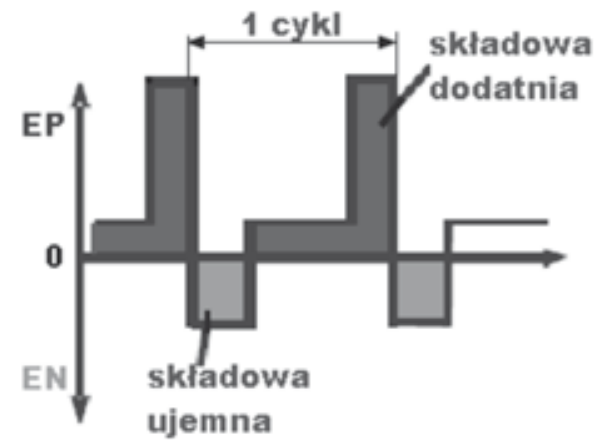

Rys. 1. Pulsacja prądu z udziałem składowej AC w urządzeniu DW 300 Fig. 1. Arc pulsation involving the $A C$ component of in the device DW 300

\section{Materiały podstawowe i dodatkowe}

Złącza próbne, pokazane na rysunku 2, wykonano z następujących materiałów:

- blachy ze stali niestopowej niskowęglowej przeznaczonej do obróbki plastycznej na zimno DC01 o grubości $0,8 \mathrm{~mm}$ z pokryciem cynkowym o grubości $12 \mu \mathrm{m}$;

- blachy ze stopu aluminium AW 6061 wg PN-EN 573-3 o grubości $1 \mathrm{~mm}$;

- drutu spawalniczego AlSi5 o średnicy 0,8 mm.

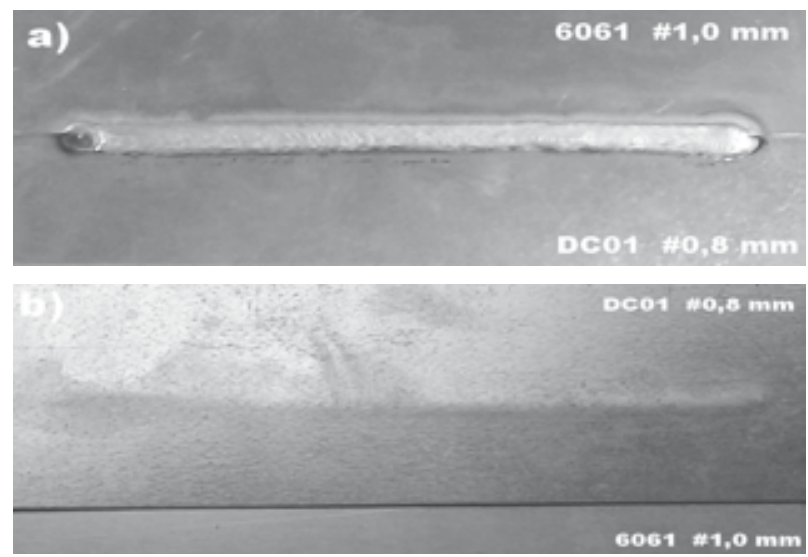

Rys. 2. Złącze próbne lutospawane metodą AC puls MIG: a) lico, b) strona odwrotna złącza

Fig. 2. The view of test joint braze welded by AC pulse MIG: a) face, b) opposite side of joint
Skład chemiczny materiałów użytych do badań przedstawiono w tablicy I.

Przedstawiona na rysunku 2 lutospoina jest wysokiej jakości, ma delikatnie łuskowate lico o równej szerokości. Przy brzegu lutospoiny zarówno od strony lica, jak i po przeciwnej stronie złącza nie ma uszkodzeń ochronnej powłoki cynku oraz nadtopień stopu aluminium 6061, natomiast widoczne jest oczyszczające działanie łuku na stopie aluminium.

\section{Próby wytrzymałościowe}

Statyczną próbę ścinania zakładkowych złączy lutospawanych wykonano przez rozciąganie na maszynie wytrzymałościowej Luis Schopper w zakresie pomiarowym do $20 \mathrm{kN}$ [10].

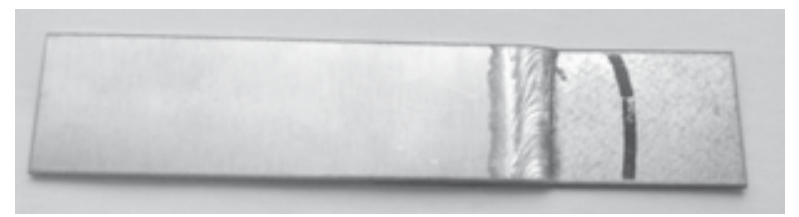

Rys. 3. Próbki złącza lutospawanego spoiwem AISi5 łukiem AC puls przed próbą rozciągania

Fig. 3. Samples of joint braze welded with AISi5 filler metal using AC pulse arc before tensile test

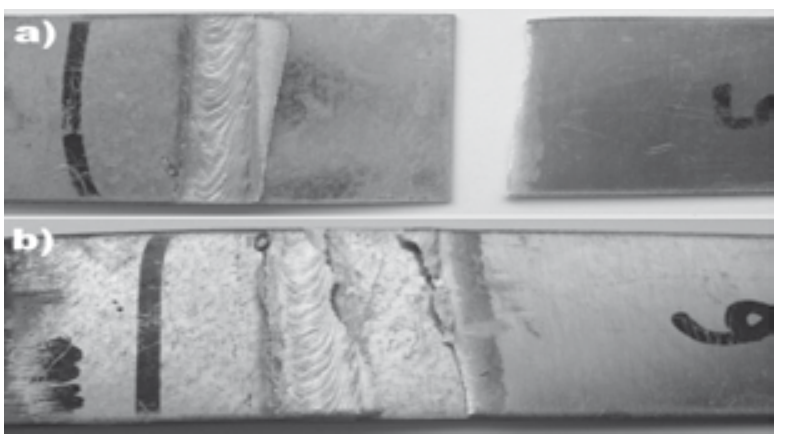

Rys. 4. Przełomy próbek złącza lutospawanego spoiwem AISi5 łukiem AC puls po rozciąganiu: a) zerwanie w SWC stopu AW6061, b) zerwanie częściowo w lutospoinie i SWC stopu 6061

Fig. 4. Fractures of braze welded joints with AISi5 filler metal using AC pulse arc after tensile: a) fracture in SWC 6061, b) fracture partialy in braze weld and SWC of AW6061 alloy

Tablica I. Zawartość pierwiastków stopowych w materiałach użytych do badań

Table I. The content of alloying elements in the materials used in the test

\begin{tabular}{|c|c|c|c|c|c|c|c|c|}
\hline \multicolumn{9}{|c|}{ Średnie stężenie pierwiastków w \% wag., reszta Fe } \\
\hline \multirow{2}{*}{ DC01 } & $\mathrm{C}$ & $\mathrm{Mn}$ & $\mathrm{Si}$ & $\mathrm{Cr}$ & $\mathrm{Ni}$ & $S$ & $P$ & $\mathrm{Cu}$ \\
\hline & 0,12 & 0,6 & - & - & - & 0,045 & 0,045 & - \\
\hline \multicolumn{9}{|c|}{ Średnie stężenie pierwiastków w \% wag., reszta Al } \\
\hline \multirow{2}{*}{ AW6061 } & $\mathrm{Mg}$ & $\mathrm{Si}$ & $\mathrm{Fe}$ & $\mathrm{Cu}$ & $\mathrm{Mn}$ & $\mathrm{Ti}$ & $\mathrm{Zn}$ & $\mathrm{Cr}$ \\
\hline & $0,8-1,2$ & $0,4-0,8$ & $<0,7$ & $0,15-0,4$ & $<0,15$ & $<0,15$ & $<0,25$ & $0,04-0,35$ \\
\hline \multicolumn{9}{|c|}{ Średnie stężenie pierwiastków w \% wag., reszta Al } \\
\hline \multirow{2}{*}{$\begin{array}{c}\text { S Al 4043A } \\
(\text { AlSi5(A)) }\end{array}$} & $\mathrm{Si}$ & $\mathrm{Mn}$ & $\mathrm{Cu}$ & $\mathrm{Ti}$ & $\mathrm{Fe}$ & $\mathrm{Zn}$ & $\mathrm{Mg}$ & $\mathrm{Be}$ \\
\hline & $4,5-5,5$ & $<0,15$ & $<0,3$ & $<0,15$ & $<0,6$ & $<0,1$ & $<0,2$ & $<0,0003$ \\
\hline
\end{tabular}


Przykładową próbkę przed próbą ścinania (rozciąganie złącza) pokazano na rysunku 3 , a przełomy próbek po rozciąganiu na rysunku 4.

Wytrzymałość na ścinanie złączy lutospawanych spoiwem AISi5 dla czterech próbek wynosiła w granicach $178 \div 220 \mathrm{MPa}$. Mniejszą wytrzymałość na ścinanie miały złącza, w których przełom obejmował częściowo lutospoinę, a częściowo SWC stopu aluminium.

\section{Badania metalograficzne}

Obserwację makrostruktur złączy lutospawanych wykonano na mikroskopie świetlnym Olympus SZX7 przy powiększeniu 10 $\div 50 x$, natomiast obserwacje mikroskopowe przeprowadzono na mikroskopie Olympus CK40M przy powiększeniu 100 i 500x. Na rysunku 5 pokazano przykładowe makrostruktury badanych złączy.
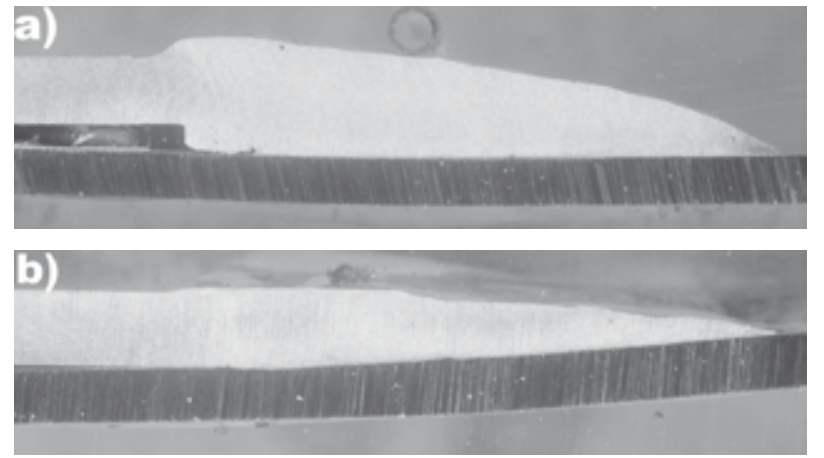

Rys. 5. Makrostruktury złączy lutospawanych spoiwem AlSi5: a) ze szczeliną między blachami, b) bez szczeliny między blachami Fig 5. Microstructure of joints braze welded with AISi5 filler metal: a) with the gap between the plates, b) without gap between the plates

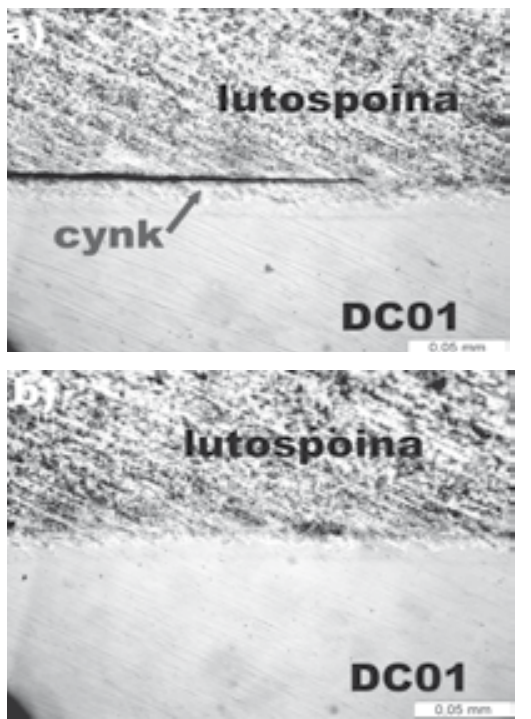

Rys. 6. Mikrostruktury złączy lutospawanych spoiwem AISi5: a) początek złącza, b) środek złącza

Fig 6. Microstructures of joints braze welded with AISi5 filler metal: a) the beginning of the joint, b) the center of the joint
Makrostruktury badanych lutospawanych złączy wykazały ich poprawną budowę, bez obecności niezgodności wewnętrznych. Stopiwo dobrze zwilżyło powierzchnie stalowej ocynkowanej blachy oraz nastąpiło wtopienie w blachę stopu aluminiowego. Otrzymano poprawne złącza przy dokładnym przyleganiu blach (rys. 5b), a także przy niedokładnym dopasowaniu łączonych blach (rys. 5a). Potwierdza to przydatność tej metody lutospawania w przypadku, gdy szczelina na długości złącza zakładkowego jest zmienna, o czym wspomina się w materiałach informacyjnych urządzenia DW 300 [9].

Na rysunku 6a przedstawiono mikrostrukturę złącza z początku lutospoiny, a na rysunku $6 b$ ze środka złącza.

Warstwa cynku nie uległa uszkodzeniu nawet w szczelinie między blachami (rys. 6a), natomiast została zwilżona przez stopiwo AISi5 na pozostałej części złącza (rys. 6b).

Pogłębioną analizę wykonano na mikroskopie skaningowym, na którym przeprowadzono analizę EDX punktową w lutospoinie oraz liniową w strefie zwilżenia. Mikrofotografie SEM z tych analiz przedstawiono na rysunkach $7 \mathrm{i} 8$.

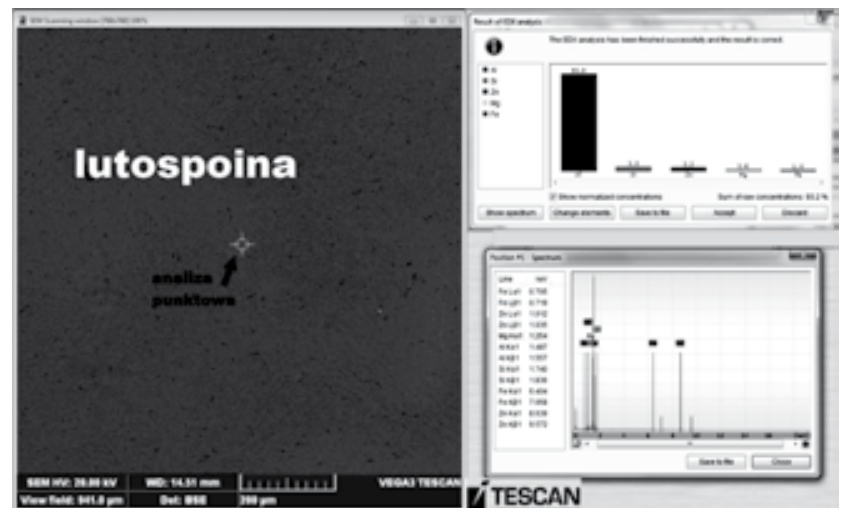

Rys. 7. Mikrofotografia SEM z analizą punktową EDX w lutospoinie AlSi5

Fig 7. SEM micrograph with a point EDX analysis in braze weld of AlSi5

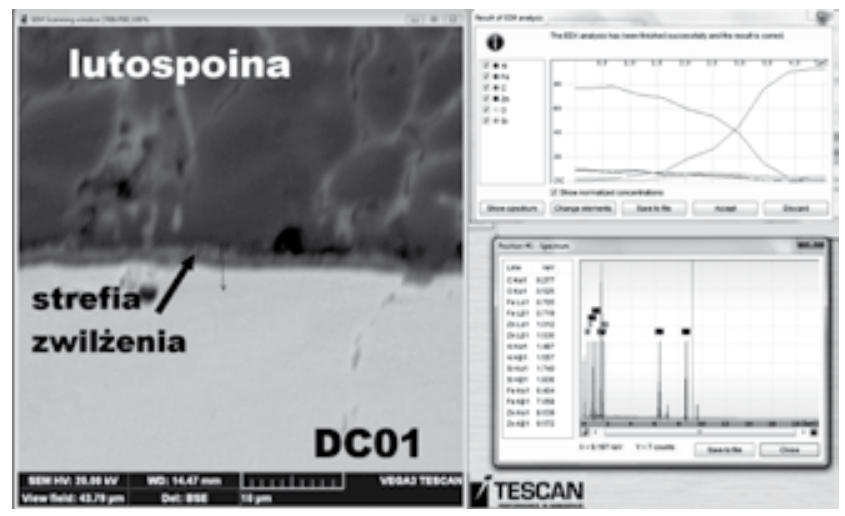

Rys. 8. Mikrofotografia SEM z analizą liniową EDX w strefie zwilżenia spoiwem AISi5 warstwy cynku na stali DC01

Fig 8. SEM micrograph with a linear EDX analysis in zone of wetting of zinc layer on DC01 steel by AISi5 filler metal 
Z analizy punktowej (rys. 7) wynika, że skład chemiczny lutospoiny zawierającej $3,3 \% \mathrm{Si}, 3,2 \% \mathrm{Zn}$, $1,6 \% \mathrm{Mg} \mathrm{i} 1,0 \% \mathrm{Fe}$ jest efektem rozpuszczenia w stopiwie AISi5 warstwy cynku oraz przetopienia części stopu aluminium 6061. Natomiast $z$ analizy liniowej (rys. 8) wynika, że początkowa warstwa cynku o grubości $12 \mu \mathrm{m}$ uległa częściowemu rozpuszczeniu w stopiwie, tworząc warstwę przejściową o grubości ok. 3,5 $\mu \mathrm{m}$, w której występuje łagodna zmiana zawartości pierwiastków stopowych.

\section{Podsumowanie}

Proces lutospawania przeprowadzono przy łączeniu blachy stalowej DC01 o grubości 0,8 mm ocynkowanej elektrolitycznie warstwą o grubości $12 \mu \mathrm{m}$ z blachą ze stopu aluminium AW6061 o grubości $1 \mathrm{~mm}$ przy użyciu spoiwa AISi5 niskoenergetyczną metodą spawania AC puls na urządzeniu DW300.

Metoda spawania AC puls umożliwiła uzyskanie poprawnych, bez wewnętrznych niezgodności i o estetycznym wyglądzie, zakładkowych złączy lutospawanych z cienkich blach. Zarówno na brzegu lutospoiny, jak i po stronie przeciwnej złącza warstwa cynku nie uległa uszkodzeniu, a zmieniająca się szczelina między blachami nie miała wpływu na jakość połączenia.

Wytrzymałość na ścinanie cienkościennych zakładkowych złączy ocynkowanej elektrolitycznie blachy stalowej DC01 z blachą ze stopu aluminium AW 6061 wykonanych spoiwem AISi5 wynosiła od 178 do $220 \mathrm{MPa}$. Wytrzymałość otrzymanych lutospawanych złączy w przybliżeniu odpowiada wytrzymałości stopu aluminium w stanie wyżarzonym występującym w strefie SWC lutospoiny.

Przeprowadzone badania wykazały możliwość wykonania metodą lutospawania wysokowytrzymałych dobrych jakościowo złączy różnoimiennych stali ocynkowanej ze stopem aluminium.

\section{Literatura}

[1] Dobrzański L. A.: Podstawy nauki o materiałach i metaloznawstwo. Materiały inżynierskie z podstawami projektowania materiałowego. Warszawa, WNT, 2006.

[2] http://asm.matweb.com/search/SpecificMaterial.asp?bassnu$\mathrm{m}=\mathrm{MA} 6061 \mathrm{t} 6$

[3] http://www.migweld.de/english/products/aluminium/ml-4043alsi5.html

[4] De Runz B.D.: Assessing the Benefits of Surface Tension Transfer Welding to Industry. Journal of Industrial Technology, vol. $19, \mathrm{nr} 4 / 2003$.

[5] De Dompablo M.: Nowe rozwiązania w technologii ColdArc i ForceArc, Przegląd Spawalnictwa, nr 7-8/2009, s. 12-16.
[6] Himmelbauer K.: The CMT process - a revolution in welding Technology, IIW Doc. No. XII-1875-05.

[7] Era T., Ide A., Uezono T., Yamamoto H., Ueyama T.: Spatter Reduction of Steel Sheets Welding Using Controlled Bridge Transfer (CBT) GMA Process. IIW Doc. No. XII-1900-06.

[8] Jastrzębski A., Tasak E.: Wpływ pulsacji łuku MIG na strukturę spoin stopów aluminium, Przegląd Spawalnictwa, nr 7-8/2009, s. 7-10.

[9] DW 300. Digital AC / DC MIG Pulse Arc Welding Machine. Cat. no 458 OTC Daihen Inc.

[10] Glezman M.: Badania właściwości złączy lutospawanych aluminium ze stalą. Praca dyplomowa, Wydział Mechaniczny, PWr, promotor dr inż. P. Białucki, Wrocław 2013.

\section{PLANY SPAWANIA - TEORIA I PRAKTYKA - JACEK SŁANIA}

\section{Cena}

Cena 1 egzemplarza książki Jacka Słani:

Plany spawania - teoria i praktyka

80 zł (w tym 5\% VAT)

W celu zamówienia książki
w Redakcji należy wypełnić formularz
zamieszczony obok i przesłać go
w formie faksu, skanu lub listu na adres:

REDAKCJA - Przegląd Spawalnictwa AW SIMP

ul. Świętokrzyska 14a, 00-050 Warszawa

tel.: 2282725 42, faks: 223361479

e-mail: pspaw@ps.pl

Wpłaty należy dokonać na rachunek bankowy: Bank BPH S.A. Oddział w Warszawie

45106000760000320000431836
Zamawiam książkę Plany spawania - teoria i praktyka

w Redakcji Przegląd Spawalnictwa w ilości .... egz.

Imię i nazwisko

Firma

Adres

NIP

Kontakt do osoby zamawiającej:

Oświadczam, że jestem podatnikiem VAT i upoważniam firmę do wystawienia faktury bez podpisu 